\title{
Management of patients with heart failure in clinical practice: differences between men and women
}

\author{
M J Lenzen, ${ }^{1}$ A Rosengren, ${ }^{2}$ W J M Scholte op Reimer, ${ }^{1} \mathrm{~F}$ Follath, ${ }^{3}$ E Boersma, ${ }^{1}$ \\ M L Simoons, ${ }^{1}$ J G F Cleland, ${ }^{4}$ M Komajda ${ }^{5}$
}

${ }^{1}$ Department of Cardiology, Erasmus Medical Center, Rotterdam, The Netherlands;

${ }^{2}$ Sahlgrenska University Hospital/Östra, Göteborg Sweden; ${ }^{3}$ Department of Internal Medicine, University Hospital Zürich, Switzerland;

${ }^{4}$ Department of Cardiology, Castle Hill Hospital, Kingston upon Hull, United Kingdom; ${ }^{5}$ Department of Cardiology, Pitié-Salpêtrière Hospital, Paris, France

Correspondence to: M J Lenzen, Department of Cardiology, room Ba 561, Erasmus Medical Center, P.O. Box 2040, 3000 CA Rotterdam, The Netherlands; m.lenzen@ erasmusmc.nl

Accepted 27 February 2007 Published Online First

17 June 2007

\begin{abstract}
Objectives: This study evaluated gender differences in clinical characteristics, treatment and outcome among patients with heart failure, and to what extent these differences are due to age and differences in left ventricular (LV) function. Although gender differences are observed among heart failure patients, few studies have been adequately powered to investigate these differences.
\end{abstract}

Methods: A total of 8914 (out of 10701 ) patients (47\% women) from the Euro Heart Survey on Heart Failure with confirmed diagnosis of heart failure were included in the analyses.

Results: Women were older (74.7 vs 68.3 years, $\mathrm{p}<0.001)$, and less often had evidence of coronary artery disease ( $56 \%$ vs $66 \%$, age-adjusted odds ratio (OR) 0.62 ; $95 \% \mathrm{Cl} 0.57$ to 0.68$)$. Women were more likely to have hypertension, diabetes, or valvular heart disease. Fewer women had an investigation of LV function $159 \%$ vs $74 \%$, age-adjusted OR 0.67; $95 \% \mathrm{Cl} 0.61$ to 0.74$)$, and, among those investigated, fewer had moderate/severe left ventricular systolic dysfunction $144 \%$ vs $71 \%$, ageadjusted OR 0.35; 95\% Cl 0.32 to 0.39). Drugs with a documented impact on survival, that is ACE-inhibitors and $\beta$-blockers, were given less often to women, even in the adjusted analysis (OR 0.72; $95 \% \mathrm{Cl} 0.61$ to 0.86 and $\mathrm{OR}$ 0.76 ; $95 \% \mathrm{Cl} 0.65$ to 0.89 , respectively). 12-week mortality was similar for men and women.

Conclusions: Fewer women had an assessment of LV function, but, when investigated, women had better ventricular function. Women were less often treated with evidence-based drugs, even after adjustment for age and important clinical characteristics. Clinicians need to be aware of deficiencies in the treatment of women with heart failure and measures should be taken to rectify them.

Chronic heart failure is a major cause of morbidity and mortality, and the reason for at least $20 \%$ of all hospital admissions in patients older than 65 years. ${ }^{12}$ Major advances over the last two decades in the diagnosis and treatment of heart failure have proven highly effective in reducing morbidity and mortality among both men and women. However, survival is still poor among both men and women, and the absolute number of women dying of heart failure each year still increases. ${ }^{3}$ Men and women with heart failure have different clinical characteristics, in that women are older and have more hypertension but less evidence of coronary heart disease and better ventricular function than men with heart failure. ${ }^{3}$ Few studies have been adequately powered to investigate how many of these known differences between men and women are due to gender alone, and how many are due to known other differences such as the discrepancies in age, ventricular function, or cause of heart failure. The large number of both men and women enrolled in the Euro Heart Survey on Heart Failure (EHS-HF) and the extensive data collection of patient characteristics, investigations and treatment provide a unique opportunity to analyse gender differences in patients with confirmed or suspected heart failure.

\section{METHODS}

We performed a comparison of men and women who were enrolled in the EHS-HF. The design details of this observational study, which was undertaken between March 2000 and May 2001, were published previously. ${ }^{45}$ Briefly, the case notes of consecutive discharges and deaths in the departments of cardiology, cardiovascular surgery, general internal medicine, non-vascular surgery and geriatrics were reviewed over a 6-week period to screen patients for:

1. a clinical diagnosis of heart failure recorded during the admission;

2. a diagnosis of heart failure recorded in the hospital notes at any time in the last 3 years;

3. administration of a loop diuretic for any reason other than renal failure within $24 \mathrm{~h}$ of death or discharge;

4. pharmacological treatment for heart failure or ventricular dysfunction within $24 \mathrm{~h}$ of death or discharge (investigators were asked to review any prescription of ACE-inhibitors, $\beta$ blockers, diuretics, digitalis or spironolactone to determine the reason for their administration).

All patients who fulfilled at least one of these criteria had a detailed record of the events precipitating their admission, cardiovascular investigation, cardiovascular and non-cardiovascular disease and therapy completed by an investigator at each site. Surviving patients were contacted and asked to attend an interview at 12 weeks, at which time any further clinical events, investigations and treatment were recorded and a brief examination was performed. Median (quartiles) follow-up was 12 (11-14) weeks.

From a total of 46788 deaths and discharges from 115 hospitals in 24 ESC member countries, 10701 patients with suspected or confirmed heart failure were enrolled in the EHS-HF. As we acknowledge the fact that the validity of heart failure diagnosis in all included patients may be challenged, we restricted the analyses to patients with a clinical diagnosis of heart failure during the 
current admission or diagnosed within the past 3 years $(\mathrm{n}=8953)$. After exclusion of 39 patients with missing data for age and gender, the total study population consisted of 8914 patients.

CAD was defined as a history of coronary revascularisation procedure, myocardial infarction or angina pectoris. Patients were considered to have left ventricular systolic dysfunction (LVSD) if they had a left ventricular ejection fraction of $<40 \%$, or moderate or severe impairment of left ventricular (LV) systolic function on echocardiography. Patients with an ejection fraction of $\geqslant 40 \%$, as well as patients with a normal or only mildly depressed LV systolic function, were classified as having preserved LV function (PLVF).

\section{Statistical analysis}

Continuous variables are described as mean values with their corresponding standard deviation (SD), and dichotomous variables are described as counts and percentages. To evaluate the differences in clinical characteristics between men and women, $\chi^{2}$ tests and Student $t$ tests were applied as appropriate. In addition, univariate and multivariate analyses were performed to study the association in clinical variables and outcome between men and women. In the multivariate analyses we adjusted for age and a number of clinical variables with a $p$ value of $<0.10$. These variables included history of hypertension, diabetes, stroke or transient ischaemic attack (TIA), respiratory disease, coronary artery disease, cardiomyopathy, and atrial fibrillation. We report odds ratios (OR) and corresponding $95 \%$ confidence intervals (CI). For all tests, a $p$ value of $<0.05$ (two-sided) was considered statistically significant. All calculations were performed using the SPSS 12.0.1 software package.

\section{RESULTS}

In table 1, the baseline characteristics of the 8914 patients (47\% women) with suspected or confirmed heart failure are summarised. Women were significantly older than men (74.7 versus 68.3 years, $p<0.001)$ with more patients aged $>80$ years $(36 \%$ versus $18 \%, p<0.001)$. A history of hypertension and diabetes was more prevalent among women, whereas men more often were smokers and heavy alcohol drinkers. Fifty-six per cent of the women but $66 \%$ of the men had known CAD ( $p<0.001)$, and corresponding figures for coronary revascularisation were $17 \%$ and $35 \% \quad(p<0.001)$, respectively. Older patients ( $\geqslant 70$ years) had more co-morbid conditions such as stroke (19\% versus $12 \%, p<0.001)$, a history of renal dysfunction (serum creatine $>150 \mathrm{mmol} / \mathrm{l})(22 \%$ versus $15 \%, \mathrm{p}<0.001)$, or atrial fibrillation (49\% versus $37 \%, \mathrm{p}<0.001)$.

Table 2 shows that women were admitted to a cardiology ward less often than men $(36 \%$ versus $53 \%$, p $<0.001)$. Left ventricular function was measured less often in women $(59 \%$ versus $74 \%, p<0.001)$, and, when it was measured, fewer women had left ventricular systolic dysfunction (44\% versus $71 \%, p<0.001)$. In a subgroup of patients who had an echocardiogram, valvular heart disease was seen more often in women $(42 \%$ versus $36 \%, p<0.001)$. The most frequently observed valvular heart disease was mitral regurgitation (31\% and $29 \%$ for men and women, respectively $(p=0.05)$ ). In addition to these gender differences, it is also important to note that younger patients were more likely to be admitted to cardiology wards (64\% versus $34 \%, p<0.001)$, and more often had an assessment of the LV function (81\% versus $60 \%$, $\mathrm{p}<0.001)$.
After adjustment for age, most of the observed gender differences remained statistically significant (table 3); however, gender differences with respect to stroke or TIA, atrial fibrillation and aortic regurgitation did not persist after adjustment for age. Irrespective of left ventricular function, women were more likely to have hypertension but less often a history of an ischaemic heart disease (table 4).

Men and women differed with respect to pharmacological treatment (table 5). Fewer women with evidence of LVSD $(n=3584)$ were treated with drugs with a documented impact on survival (ACE-inhibitors (OR $0.71 ; 95 \%$ CI 0.60 to 0.84 ), $\beta$ blockers (OR $0.66 ; 95 \%$ CI 0.57 to 0.77 ), and spironolactone (OR $0.69 ; 95 \%$ CI 0.59 to 0.81 ), whereas they were more often treated with cardiac glycosides (OR 1.16; 95\% CI 1.05 to 1.28). In addition, women were also less likely to be treated with antithrombotic drugs (OR 0.66; 95\% CI 0.59 to 0.75). After adjustment for age and clinical characteristics including $\mathrm{CAD}$, these observed gender differences remained significant. We repeated the analyses in a subgroup of patients who had PLVF $(n=2396)$. In this subgroup of patients no significant gender differences were observed with respect to ACE-inhibitors, $\beta$ blockers, and spironolactone. Conversely, gender differences were observed regarding the administration of diuretics, cardiac glycosides, and antithrombotic agents.

Patients with evidence of LVSD, admitted to cardiology wards (including cardiovascular surgery), were treated more often with ACE-inhibitors (81\%), $\beta$-blockers (55\%), and spironolactone $(32 \%)$ than patients admitted to general internal medicine wards $(75 \%, 30 \%$, and $27 \%$ respectively) or patients admitted on non-vascular surgery or geriatric wards $(66 \%, 32 \%$, and $21 \%$ respectively).

No substantial gender differences could be demonstrated with respect to 12 -week mortality and readmission within 12 weeks (table 6). Although the percentage of women who died during the observation period was slightly higher (15.2\% versus $12.7 \%$ ), gender was not an independent predictor of mortality (OR 1.10; 95\% CI 0.88 to 1.38 for patients with LVSD, and OR 1.23 ; $95 \%$ CI 0.93 to 1.64 for patients with PLVF).

\section{DISCUSSION}

This study confirms earlier reports that women with heart failure have a different clinical profile from that seen in men, and more often have a preserved left ventricular function. ${ }^{36}$ These differences remained significant after adjustment for age. In addition, women were less often admitted to cardiology wards, or had an assessment of left ventricular function, and were also less often treated with evidence-based drugs. The observed differences were still evident after adjustment for age and other clinical variables. Despite the fact that women had better left ventricular systolic function and less often had CAD, outcomes with respect to in-hospital and total 12-week mortality were similar in men and women.

Consistent with previous reports, women were older, more often had hypertension, diabetes, cerebrovascular disease, and valvular heart disease, but had a lower prevalence of CAD and LVSD. $^{3}{ }^{6-9}$ Because women were less likely to undergo assessment of the left ventricular function a substantial proportion could not be identified as having depressed or preserved left ventricular function. Although this gender difference with respect to lack of information on ventricular function confirms results from other studies, ${ }^{10}{ }^{11}$ the fact that women were less likely than men to undergo qualitative or quantitative assessment of left ventricular function causes concern, because this information is critical to confirm heart failure, to provide 
Table 1 Baseline characteristics by sex and age

\begin{tabular}{|c|c|c|c|c|c|c|c|c|c|c|}
\hline & \multirow[b]{2}{*}{$\begin{array}{l}\text { Total } \\
(\mathrm{n}=8914)\end{array}$} & \multicolumn{3}{|c|}{ All patients $(n=8914)$} & \multicolumn{3}{|c|}{ Patients $<70$ years $(n=3520)$} & \multicolumn{3}{|c|}{ Patients $\geqslant 70$ years $(n=5394)$} \\
\hline & & $\begin{array}{l}\text { Men }(\%) \\
(n=4748)\end{array}$ & $\begin{array}{l}\text { Women }(\%) \\
(\mathrm{n}=4166)\end{array}$ & p Value & $\begin{array}{l}\text { Men (\%) } \\
\text { (n = 2368) }\end{array}$ & $\begin{array}{l}\text { Women }(\%) \\
(n=1152)\end{array}$ & p Value & $\begin{array}{l}\text { Men }(\%) \\
(n=2380)\end{array}$ & $\begin{array}{l}\text { Women (\%) } \\
(\mathrm{n}=3014)\end{array}$ & p Value \\
\hline Age (mean, SD) & $71.3(12.7)$ & $68.3(12.7)$ & $74.7(11.9)$ & $<0.001$ & $58.3(9.0)$ & $59.8(9.1)$ & $<0.001$ & $78.3(6.4)$ & $80.5(6.7)$ & $<0.001$ \\
\hline$<60$ & 1523 & 23 & 11 & $<0.001$ & 47 & 36 & $<0.001$ & - & - & \\
\hline $60-69$ & 1997 & 27 & 18 & $<0.001$ & 53 & 64 & $<0.001$ & - & - & \\
\hline $70-79$ & 3014 & 32 & 36 & $<0.001$ & - & - & & 64 & 50 & $<0.001$ \\
\hline Heavy alcohol drinker, ever & 564 & 11 & 1 & $<0.001$ & 15 & 2 & $<0.001$ & 7 & 1 & $<0.001$ \\
\hline History of hypertension & 4771 & 49 & 59 & $<0.001$ & 48 & 58 & $<0.001$ & 49 & 60 & $<0.001$ \\
\hline Diabetes & 2457 & 26 & 29 & $<0.001$ & 26 & 30 & 0.006 & 26 & 29 & 0.02 \\
\hline $\begin{array}{l}\text { Stroke or transient ischaemic } \\
\text { attack (TIA) }\end{array}$ & 1468 & 16 & 18 & 0.02 & 11 & 14 & 0.05 & 20 & 19 & 0.38 \\
\hline History of renal dysfunction & 1688 & 21 & 17 & $<0.001$ & 15 & 14 & 0.18 & 26 & 18 & $<0.001$ \\
\hline $\begin{array}{l}\text { Revascularisation (PCI or } \mathrm{CABG} \text { ), } \\
\text { ever }\end{array}$ & 1484 & 35 & 17 & $<0.001$ & 44 & 28 & $<0.001$ & 26 & 13 & $<0.001$ \\
\hline Dilated cardiomyopathy & 240 & 4 & 2 & $<0.001$ & 5 & 3 & 0.008 & 2 & 1 & $<0.001$ \\
\hline Atrial fibrillation (AF), ever & 3932 & 42 & 46 & $<0.001$ & 36 & 37 & 0.63 & 48 & 50 & 0.21 \\
\hline Chronic AF & 2202 & 24 & 26 & 0.01 & 19 & 20 & 0.41 & 29 & 28 & 0.80 \\
\hline
\end{tabular}

$\uparrow C A D$ (coronary artery disease): myocardial infarction, angina, or revascularisation.

optimal treatment and to estimate prognosis. ${ }^{12}$ Although our study did not identify reasons for the observed diagnostic deficiency, we were able to exclude age and a number of clinical characteristics as important confounders.

As discussed in previous reports, recommended drugs in patients who were enrolled in the EHS-HF were underused..$^{13} 14$ The current study adds another dimension to this observation, namely that men and women were treated differently.
Univariate analyses revealed that women were less likely to be treated with drugs that have a proven effect on reducing mortality (ACE-I, $\beta$-blockers, and spironolactone), but were treated more often with cardiac glycosides and diuretics. Although the observed differences decreased after adjustment for age and a number of clinical characteristics, drugs with a proven effect on reducing mortality were still prescribed to women less often than to men. This indicates that older age and

Table 2 Clinical characteristics by sex and age

\begin{tabular}{|c|c|c|c|c|c|c|c|c|c|c|}
\hline & \multirow[b]{2}{*}{$\begin{array}{l}\text { Total } \\
(\mathrm{n}=8914)\end{array}$} & \multicolumn{3}{|c|}{ All patients $(\mathrm{n}=8914)$} & \multicolumn{3}{|c|}{ Patients $<70$ years $(n=3520)$} & \multicolumn{3}{|c|}{ Patients $\geqslant 70$ years $(n=5394)$} \\
\hline & & $\begin{array}{l}\text { Men (\%) } \\
(n=4748)\end{array}$ & $\begin{array}{l}\text { Women }(\%) \\
(n=4166)\end{array}$ & p Value & $\begin{array}{l}\text { Men }(\%) \\
(\mathrm{n}=2368)\end{array}$ & $\begin{array}{l}\text { Women (\%) } \\
(n=1152)\end{array}$ & p Value & $\begin{array}{l}\text { Men }(\%) \\
(n=2380)\end{array}$ & $\begin{array}{l}\text { Women }(\%) \\
(n=3014)\end{array}$ & p Value \\
\hline \multicolumn{11}{|l|}{ Ward of admission: } \\
\hline $\begin{array}{l}\text { Cardiology (incl. cardiovascular } \\
\text { surgery) }\end{array}$ & 4041 & 53 & 36 & $<0.001$ & 67 & 56 & $<0.001$ & 39 & 29 & $<0.001$ \\
\hline General internal medicine & 5165 & 40 & 55 & $<0.001$ & 28 & 40 & $<0.001$ & 51 & 60 & $<0.001$ \\
\hline Non-vascular surgery or geriatrics & 708 & 7 & 9 & $<0.001$ & 4 & 4 & $<0.001$ & 10 & 11 & $<0.001$ \\
\hline $\begin{array}{l}\text { Assessment of left ventricular (LV) } \\
\text { function }\end{array}$ & 5980 & 74 & 59 & $<0.001$ & 84 & 76 & $<0.001$ & 65 & 53 & $<0.001$ \\
\hline LVSD & 3584 & 71 & 44 & $<0.001$ & 74 & 48 & $<0.001$ & 66 & 42 & $<0.001$ \\
\hline LVEF measured, ever & 5532 & 69 & 54 & $<0.001$ & 80 & 71 & $<0.001$ & 58 & 48 & $<0.001$ \\
\hline Ejection fraction $<40 \%$ & 2089 & 47 & 24 & $<0.001$ & 52 & 27 & $<0.001$ & 42 & 22 & $<0.001$ \\
\hline Echocardiography performed: & 6023 & 73 & 61 & $<0.001$ & 82 & 76 & $<0.001$ & 65 & 56 & $<0.001$ \\
\hline Normal/mild LV systolic function & 2560 & 33 & 55 & $<0.001$ & 30 & 53 & $<0.001$ & 37 & 57 & $<0.001$ \\
\hline $\begin{array}{l}\text { Moderate/severe LV systolic } \\
\text { dysfunction }\end{array}$ & 2861 & 58 & 33 & $<0.001$ & 62 & 38 & $<0.001$ & 53 & 31 & $<0.001$ \\
\hline LV dilatation & 1597 & 35 & 14 & $<0.001$ & 41 & 18 & $<0.001$ & 28 & 13 & $<0.001$ \\
\hline Moderate/severe diastolic dysfunction & 759 & 15 & 10 & $<0.001$ & 16 & 9 & $<0.001$ & 13 & 10 & 0.002 \\
\hline Mitral stenosis & 185 & 2 & 5 & $<0.001$ & 2 & 6 & $<0.001$ & 1 & 5 & $<0.001$ \\
\hline Aortic stenosis & 444 & 6 & 9 & $<0.001$ & 4 & 6 & 0.18 & 8 & 11 & 0.001 \\
\hline Mitral regurgitation & 1778 & 29 & 31 & 0.05 & 30 & 26 & 0.06 & 27 & 33 & $<0.001$ \\
\hline Aortic regurgitation & 448 & 7 & 8 & 0.01 & 6 & 6 & 0.55 & 8 & 10 & 0.13 \\
\hline
\end{tabular}

fLVSD $=$ ejection fraction $<40 \%$ or moderate to severe LV systolic dysfunction. 
Table 3 Unadjusted and adjusted ORs for the association in clinical characteristics between men and women (total population, $n=8914$ )

\begin{tabular}{|c|c|c|}
\hline & \multicolumn{2}{|c|}{ Gender differences (reference group is men) } \\
\hline & $\begin{array}{l}\text { Unadjusted } O R^{*} \\
(95 \% \mathrm{Cl})\end{array}$ & $\begin{array}{l}\text { OR* adjusted for age } \\
(95 \% \mathrm{Cl})\end{array}$ \\
\hline Current smoker & $0.28(0.24$ to 0.33$)$ & 0.36 (0.31 to 0.42$)$ \\
\hline Heavy alcohol drinker, ever & 0.10 (0.07 to 0.13 ) & $0.12(0.09$ to 0.16$)$ \\
\hline History of hypertension & 1.55 (1.42 to 1.69$)$ & 1.51 (1.39 to 1.65$)$ \\
\hline Diabetes & 1.18 (1.09 to 1.30$)$ & $1.17(1.06$ to 1.29$)$ \\
\hline $\begin{array}{l}\text { Stroke or transient ischaemic attack } \\
\text { (TIA) }\end{array}$ & 1.15 (1.03 to 1.28$)$ & $0.98(0.87$ to 1.10$)$ \\
\hline History of renal dysfunction & $0.79(0.71$ to 0.87$)$ & $0.67(0.60$ to 0.75$)$ \\
\hline Respiratory disease & $0.92(0.84$ to 1.00$)$ & $0.84(0.77$ to 0.93$)$ \\
\hline Cumulative evidence for $\mathrm{CAD} \dagger$ & 0.65 (0.60 to 0.71 ) & $0.62(0.57$ to 0.68$)$ \\
\hline Dilated cardiomyopathy & 0.40 (0.30 to 0.53$)$ & 0.57 (0.42 to 0.77$)$ \\
\hline Atrial fibrillation, ever & 1.18 (1.09 to 1.29$)$ & $1.03(0.95$ to 1.13$)$ \\
\hline \multicolumn{3}{|l|}{ Ward of admission: } \\
\hline Cardiology & 0.50 (0.46 to 0.54$)$ & $0.66(0.61$ to 0.73$)$ \\
\hline General internal medicine & 1.85 (1.70 to 2.01$)$ & $1.47(1.35$ to 1.61$)$ \\
\hline Other ward & 1.30 (1.11 to 1.51$)$ & 1.01 (0.86 to 1.18$)$ \\
\hline Assessment of LV function: & 0.51 (0.47 to 0.56 ) & 0.67 (0.61 to 0.74$)$ \\
\hline LVSD & 0.33 (0.29 to 0.37$)$ & 0.35 (0.32 to 0.39$)$ \\
\hline Echocardiography performed: & 0.57 (0.52 to 0.62$)$ & $0.74(0.67$ to 0.81$)$ \\
\hline Mitral stenosis & 3.54 (2.57 to 4.89 ) & 3.89 (2.79 to 5.41$)$ \\
\hline Aortic stenosis & 1.66 (1.37 to 2.01$)$ & 1.39 (1.14 to 1.70$)$ \\
\hline Mitral regurgitation & $1.12(1.00$ to 1.25$)$ & $1.12(1.00$ to 1.25$)$ \\
\hline Aortic regurgitation & $1.28(1.05$ to 1.55$)$ & $1.17(0.96$ to 1.42$)$ \\
\hline
\end{tabular}

a different clinical profile in women do not altogether explain the observed gender differences in pharmacological treatment between men and women. It is in this context important to
Table 4 Age, hypertension and CAD by gender and left ventricular function among patients with known LV function $(n=5980)$

\begin{tabular}{|c|c|c|c|}
\hline & $\begin{array}{l}\text { Men } \\
(n=3513)\end{array}$ & $\begin{array}{l}\text { Women } \\
(\mathrm{n}=2467)\end{array}$ & $\begin{array}{l}O R^{*} \text { adjusted } \\
\text { for age }(95 \% \mathrm{CI})\end{array}$ \\
\hline Left ventricular systolic dysfunction (n) & 2490 & 1094 & \\
\hline Mean age (SD) & $65.7(12.4)$ & $71.1(12.6)$ & \\
\hline History of hypertension (\%) & $1179(47)$ & $628(57)$ & 1.50 (1.30 to 1.7 \\
\hline Myocardial infarction, ever (\%) & $1383(56)$ & $528(48)$ & 0.67 (0.58 to 0.78 \\
\hline History of angina (\%) & $1191(48)$ & $500(46)$ & $0.85(0.74$ to 0.99$)$ \\
\hline Revascularisation (PCl, CABG) (\%) & $687(28)$ & $175(16)$ & 0.53 (0.44 to 0.63 \\
\hline Cumulative evidence for $\mathrm{C}$ & $1754(70)$ & $720(66)$ & 0.68 (0.58 to 0.8 \\
\hline Preserved left ventricular function ( $\mathrm{n}$ ) & 1023 & 1373 & \\
\hline Mean age (SD) & $68.3(12.6)$ & $72.9(11.6)$ & \\
\hline History of hypertension (\%) & $559(55)$ & $880(64)$ & $1.42(1.20$ to 1.67$)$ \\
\hline Myocardial infarction, ever (\%) & $377(37)$ & $311(23)$ & $0.49(0.41$ to 0.59$)$ \\
\hline History of angina $(\%)$ & $499(48)$ & $547(40)$ & 0.69 (0.58 to 0.81 \\
\hline Revascularisation (PCl, CABG) (\%) & $238(23)$ & $146(11)$ & $0.42(0.34$ to 0.53$)$ \\
\hline Cumulative evidence for $\mathrm{CAD} \uparrow(\%)$ & $656(64)$ & $726(53)$ & 0.61 (0.51 to 0.7 \\
\hline
\end{tabular}

${ }^{*} \mathrm{OR}>1$ correlates with a higher prevalence in women.

†CAD (coronary artery disease): myocardial infarction, angina, or revascularisation.

$\mathrm{PCl}$, percutaneous coronary intervention; $\mathrm{CABG}$, coronary artery bypass grafting.

note that guidelines do not discriminate between men and women, and treatment with evidence-based drugs is advocated in all patients with heart failure and left ventricular dysfunction. ${ }^{12}$ However, women are known to have more side effects when treated with ACE-I, ${ }^{15}{ }^{16}$ and the use of cardiac glycosides may even be associated with an increased mortality among women, but not men, with LVSD. ${ }^{17}$

In our study, no differences were observed in the adjusted analyses regarding in-hospital and 12 -week mortality despite the fact that women were less likely to be diagnosed with $\mathrm{CAD}$ or LVSD, both markers of increased risk. The lack of a sex difference in mortality is consistent with a large Italian

Table 5 Pharmacological treatment by gender, including unadjusted and adjusted ORs for the association with treatment (incl. total population and stratified to patients with depressed and preserved left ventricular function)

\begin{tabular}{|c|c|c|c|c|c|}
\hline & & & \multicolumn{3}{|l|}{ Gender differences } \\
\hline & & & $\begin{array}{l}\text { Unadjusted } O R^{*} \\
(95 \% \mathrm{CI})\end{array}$ & $\begin{array}{l}\text { OR* adjusted for age } \\
(95 \% \mathrm{Cl})\end{array}$ & $\begin{array}{l}\text { Adjusted OR* } \\
(95 \% \mathrm{CI}) \dagger\end{array}$ \\
\hline ACE-inhibitors & 69 & 60 & 0.67 (0.62 to 0.74$)$ & $0.77(0.70$ to 0.84$)$ & $0.70(0.64$ to 0.77$)$ \\
\hline$\beta$-Blockers & 41 & 32 & $0.70(0.65$ to 0.77$)$ & $0.86(0.79$ to 0.94$)$ & 0.90 (0.83 to 0.99$)$ \\
\hline Spironolactone & 26 & 19 & $0.67(0.61$ to 0.75$)$ & $0.76(0.69$ to 0.85$)$ & $0.77(0.69$ to 0.85$)$ \\
\hline Antithrombotic agents & 82 & 75 & 0.65 (0.58 to 0.71$)$ & $0.67(0.60$ to 0.74$)$ & 0.71 (0.63 to 0.79$)$ \\
\hline Patients with LVSD $(n=3584)$ & Men $(n=2490)(\%)$ & Women ( $n=1094)$ (\%) & & & \\
\hline ACE-inhibitors & 80 & 74 & $0.71(0.60$ to 0.84$)$ & $0.77(0.65$ to 0.91$)$ & 0.72 (0.61 to 0.86$)$ \\
\hline$\beta$-Blockers & 49 & 39 & 0.66 (0.57 to 0.77$)$ & 0.76 (0.66 to 0.88$)$ & $0.76(0.65$ to 0.89$)$ \\
\hline Spironolactone & 32 & 25 & 0.69 (0.59 to 0.81$)$ & $0.77(0.65$ to 0.91$)$ & 0.75 (0.64 to 0.89$)$ \\
\hline Diuretics & 88 & 89 & $1.18(0.94$ to 1.47$)$ & $1.06(0.84$ to 1.34$)$ & $1.04(0.82$ to 1.32$)$ \\
\hline$\beta$-Blockers & 40 & 36 & $0.85(0.72$ to 1.00$)$ & $0.95(0.80$ to 1.12$)$ & 0.98 (0.82 to 1.18$)$ \\
\hline Spironolactone & 17 & 20 & $1.22(0.99$ to 1.50$)$ & $1.24(1.00$ to 1.54$)$ & $1.22(0.98$ to 1.52$)$ \\
\hline Diuretics & 78 & 88 & 2.03 (1.63 to 2.53$)$ & 1.74 (1.39 to 2.18$)$ & 1.64 (1.30 to 2.07$)$ \\
\hline Cardiac glycosides & 28 & 37 & $1.45(1.22$ to 1.73$)$ & $1.37(1.14$ to 1.63$)$ & 1.30 (1.06 to 1.58$)$ \\
\hline Antithrombotic agents & 83 & 77 & $0.72(0.59$ to 0.88$)$ & $0.71(0.58$ to 0.88$)$ & 0.76 (0.61 to 0.94$)$ \\
\hline
\end{tabular}

LVSD, left ventricular systolic dysfunction; PLVF, preserved left ventricular function.

${ }^{*} \mathrm{OR}>1$ correlates with a higher prevalence in women.

$\uparrow$ Adjusted for age, hypertension, diabetes, stroke or transient ischaemic attack (TIA), renal failure, respiratory disease, coronary artery disease, cardiomyopathy, and atrial fibrillation. 
Table 6 Unadjusted and adjusted ORs for outcome (mortality and readmission) among women compared with men

\begin{tabular}{|c|c|c|c|c|c|}
\hline & \multirow[b]{2}{*}{ Men/Women (\%) } & \multicolumn{4}{|l|}{ Gender differences } \\
\hline & & $\begin{array}{l}\text { Unadjusted OR } \\
(95 \% \mathrm{CI})\end{array}$ & $\begin{array}{l}\text { OR adjusted for age } \\
(95 \% \mathrm{CI})\end{array}$ & $\begin{array}{l}\text { Adjusted OR, patients with } \\
\text { LVSD only, } \mathrm{n}=3584 \\
(95 \% \mathrm{CI}) \dagger\end{array}$ & $\begin{array}{l}\text { Adjusted OR, patients with } \\
\text { PLVF only, } \mathrm{n}=2396 \\
(95 \% \mathrm{CI}) \dagger\end{array}$ \\
\hline $\begin{array}{l}\text { Readmissions during } 12 \text {-week } \\
\text { follow-up period }\end{array}$ & $20.3 / 18.9$ & $0.92(0.83$ to 1.02$)$ & 0.92 (0.82 to 1.02$)$ & $1.03(0.86$ to 1.23$)$ & $0.86(0.70$ to 1.05$)$ \\
\hline
\end{tabular}

follow-up period

*0R $>1$ correlates with a higher prevalence in women.

$\uparrow$ Adjusted for age, hypertension, diabetes, stroke or transient ischaemic attack (TIA), renal failure, respiratory disease, coronary artery disease, cardiomyopathy, and atrial fibrillation.

registry, ${ }^{18}$ but contrasts with others. ${ }^{19-21}$ However, our data are limited by short-term (12-week) follow-up and lack of certainty about the preceding duration of heart failure. Studies suggest that LVEF and CAD are stronger predictors of prognosis in women, as for every $1 \%$ increase of LVEF the decrease in mortality was $4 \%$ in women versus $1 \%$ in men, and women with CAD and heart failure have a 2.5 -fold increase in the risk of mortality as compared with a 1.5-fold increase in men. ${ }^{7}$ Potentially, fewer investigations in women might have led to prognostically important information being missed.

The limitations of this study are those inherent to observational studies involving voluntarily participating hospitals for a clinical syndrome that does not have a clear, simple objective definition. Although we attempted to include a wide spectrum of hospitals in many European countries, the results will almost certainly be biased towards better than average practices. However, a high proportion of relevant patients at each centre were included (approximately 16 patients each week per centre), suggesting that the population was relatively unselected and likely to be representative of clinical practice. One of the strengths of the survey was that it included a large number of unselected and consecutively enrolled patients from multiple hospitals across Europe with both suspected and confirmed diagnosis of heart failure. We were able to perform multivariate analyses in which we could adjust for age and a number of relevant clinical characteristics.

In conclusion, in this large population of patients with a diagnosis of heart failure who were enrolled in the Euro Heart Survey on Heart Failure, we confirmed that, compared with men, women are older and more likely to have preserved left ventricular function, hypertension, diabetes, and valvular heart disease, but less likely to have a diagnosis of $\mathrm{CAD}$. Women were also less likely to be admitted to cardiology wards, or have an assessment of left ventricular function, and, in addition, were treated with guideline recommended drugs to a lesser extent than men. After adjustment for age and important clinical characteristics, the observed differences decreased, but remained statistically significant for ACE-I, $\beta$-blockers and spironolactone. Despite better left ventricular function and less CAD, women and men had similar age-adjusted 12-week mortality. There is no evidence-based justification for treating women with heart failure less intensively than men. As it is a challenge for all clinicians to ensure equal treatment for men and women, it is important that clinicians are aware of these deficiencies in the management of women with heart failure and measures should be taken to rectify them.

Acknowledgements: The authors are grateful to the Euro Heart Survey Team, national coordinators, participating centres, local investigators, and data collecting officers. The Euro Heart Survey was supported by industry sponsors and supporting institutions as published earlier. ${ }^{5}$ MJ Lenzen was supported by The Netherlands Heart Foundation (2000T101).

Competing interests: None declared.

\section{REFERENCES}

1. Jessup M, Brozena S. Heart Failure. N Engl J Med 2003;348:2007-18.

2. Khand $\mathbf{A}$, Gemmel I, Clark AL, et al. Is the prognosis of heart failure improving? J Am Coll Cardiol 2000;36:2284-6.

3. Bello N, Mosca L. Epidemiology of coronary heart disease in women. Prog Cardiovasc Dis 2004;46:287-95.

4. Cleland JGF, Swedberg K, Cohen-Solal A, et al. The Euro Heart Failure Survey of The EUROHEART Survey Programme: A survey on the quality of care among patients with heart failure in Europe. Eur $J$ Heart Fail 2000;2:123-32.

5. Cleland JGF, Swedberg K, Follath F, et al. The EuroHeart Failure survey programmea survey on the quality of care among patients with heart failure in Europe. Part 1 : patient characteristics and diagnosis. Eur Heart J 2003;24:442-63.

6. Stromberg A, Martensson J. Gender differences in patients with heart failure. Eur J Cardiovasc Nurs 2003;2:7-18.

7. Ghali JK, Krause-Steinrauf HJ, Adams KF, et al. Gender differences in advanced heart failure: insights from the BEST study. J Am Coll Cardiol 2003;42:2128-34.

8. Jessup M, Pina IL. Is it important to examine gender differences in the epidemiology and outcome of severe heart failure? J Thorac Cardiovasc Surg 2004; 127:1247-52.

9. McDonagh TA, Morrison CE, Lawrence A, et al. Symptomatic and asymptomatic left-ventricular systolic dysfunction in an urban population. Lancet 1997;350:829-33.

10. Mejhert M, Holmgren J, Wandell P, et al. Diagnostic tests, treatment and follow-up in heart failure patients--is there a gender bias in the coherence to guidelines? Eur J Heart Fail 1999;1:407-10.

11. Burns RB, McCarthy EP, Moskowitz MA, et al. Outcomes for older men and women with congestive heart failure. J Am Geriatr Soc 1997;45:276-80.

12. Swedberg K, Cleland J, Dargie H, et al. Guidelines for the diagnosis and treatment of chronic heart failure: executive summary (update 2005): The Task Force for the Diagnosis and Treatment of Chronic Heart Failure of the European Society of Cardiology. Eur Heart J 2005;26:1115-40.

13. Komajda M, Follath F, Swedberg K, et al. The EuroHeart Failure Survey programme-a survey on the quality of care among patients with heart failure in Europe: Part 2 treatment. Eur Heart J 2003;24:464-74.

14. Lenzen MJ, Boersma E, Scholte Op Reimer WJ, et al. Under-utilization of evidencebased drug treatment in patients with heart failure is only partially explained by dissimilarity to patients enrolled in landmark trials: a report from the Euro Heart Survey on Heart Failure. Eur Heart J 2005;26:2706-13.

15. Shah MR, Granger CB, Bart BA, et al. Sex-related differences in the use and adverse effects of angiotensin-converting enzyme inhibitors in heart failure: the study of patients intolerant of converting enzyme inhibitors registry. Am J Med 2000; 109:489-92.

16. Kostis JB, Shelton B, Gosselin G, et al. Adverse effects of enalapril in the Studies of Left Ventricular Dysfunction (SOLVD). SOLVD Investigators. Am Heart J 1996;131:350-5.

17. Rathore SS, Wang Y, Krumholz HM. Sex-based differences in the effect of digoxin for the treatment of heart failure. N Engl J Med 2002;347:1403-11.

18. Opasich C, Tavazzi L, Lucci D, et al. Comparison of one-year outcome in women versus men with chronic congestive heart failure. Am J Cardiol 2000;86:353-7.

19. Ho KK, Anderson KM, Kannel WB, et al. Survival after the onset of congestive heart failure in Framingham Heart Study subjects. Circulation 1993;88:107-15.

20. Schocken DD, Arrieta MI, Leaverton PE, et al. Prevalence and mortality rate of congestive heart failure in the United States. J Am Coll Cardiol 1992;20:301-6.

21. Bourassa MG, Gurne 0, Bangdiwala Sl, et al. Natural history and patterns of current practice in heart failure. The Studies of Left Ventricular Dysfunction (SOLVD) Investigators. J Am Coll Cardiol 1993;22:14A-19A. 